Cita: Freixas, Margarita (2006): "La técnica lexicográfica en el Diccionario de Autoridades: la contribución del académico Juan Ferreras", en Mar Campos Souto e Ignacio Pérez Pascual, eds., El diccionario de la Real Academia Española: ayer y hoy, A Coruña, Universidade da Coruña, Anexos de Revista de Lexicografía, 1, pp. 83-97. https://doi.org/10.17979/spudc.9788497497466.083

\title{
La técnica lexicográfica en el Diccionario de Autoridades: la contribución del académico Juan Ferreras*
}

\author{
MARGARITA FREIXAS \\ Universitat Autònoma de Barcelona
}

La documentación conservada sobre la actividad de la Real Academia Española en sus orígenes ofrece poca información acerca de la metodología empleada en la redacción del Diccionario de Autoridades (en adelante, DA). Las Actas de las reuniones de la Corporación desde su fundación en 1713 hasta la impresión del último de los tomos de su primer repertorio lexicográfico a fines de 1739 proporcionan algunos datos al respecto, rigurosamente expuestos y estudiados por Lázaro Carreter. ${ }^{1}$ En los resúmenes de las juntas, redactados por el Secretario de la Real Academia, se informa acerca de la asignación entre los académicos de distintas tareas: elaboración de listas de palabras, vaciado de voces de un corpus de textos acordado y reparto del trabajo de redacción de los artículos. Sin embargo, de la lectura de las Actas poco puede deducirse sobre las características del proceso de redacción de las entradas del $D A$ desde que éstas se asignaban a un académico (o a varios, en caso de que debiera completarse o mejorarse su trabajo) hasta que la Corporación aprobaba la redacción definitiva de los artículos, sanción imprescindible para que éstos pasaran a formar parte del repertorio lexicográfico. Ocasionalmente, las Actas compendian algunas de las discusiones y propuestas (centradas en cuestiones como la ortografía o el uso de las autoridades) que iban surgiendo al revisar las entradas en las juntas.

* La redacción de este trabajo ha sido posible gracias a una ayuda concedida por la Fundación Caja Madrid para la elaboración de mi tesis doctoral, Freixas (2003), así como investigaciones relacionadas con el $D A$. En la actualidad, estoy realizando un estudio más amplio sobre la técnica lexicográfica de los primeros académicos.

1 Lázaro Carreter (1972) elaboró un catálogo de los encargados de redactar el diccionario, acompañado de información precisa acerca de las distintas combinaciones de letras de las que se ocuparon y de la fecha en que entregaron su trabajo. En dicho catálogo se recogen, además, las fechas de las diversas revisiones a las que la Corporación sometió la redacción de las entradas. 
Además de la información que ofrecen las Actas sobre el proceso de redacción del $D A$, contamos con un precioso documento del que ya dieron noticia el Conde de la Viñaza (1893: $n^{\circ}$ 1564) y Samuel Gili Gaya (1947: xx), pero que aún está por estudiar. Se trata de unos apuntes autógrafos de Juan Ferreras, uno de los fundadores de la Real Academia Española. Se encuentran en los últimos folios (ff. $284^{r}-305^{r}$ ) de un volumen facticio de textos manuscritos y documentos impresos que pertenecieron a Ferreras y que hoy conserva la Biblioteca Nacional de España con la signatura Ms. 9232. En las anotaciones de Ferreras se encuentran diversas versiones de algunas de las entradas que redactó para el $D A$. En el manuscrito se copian algunos artículos de la combinación $A S$, desde astillero (entrada de la que se conserva la transcripción de las dos últimas líneas) hasta asymptotos (ff. $284^{\mathrm{r}}-285^{\mathrm{r}}$ ); ${ }^{2}$ después, unos Proverbios de la voz Asno (f. 286'); una serie de artículos para $A G$, de agachar y agacharse hasta aguzadera (ff. $\left.287^{\mathrm{r}}-290^{\mathrm{r}}\right) ;^{3}$ una nueva versión de éstos con importantes añadidos (ff. 291 ${ }^{\mathrm{r}}$ $296^{v}$ ); lo que parece la primera redacción de dichas entradas (ff. $297^{r}-300^{v}$ ), pues contiene mucha menos información que las versiones de los folios precedentes; y, finalmente, la primera fase en la redacción de la combinación $A S$ : un listado de palabras de as hasta asylo (ff. $301^{\mathrm{r}}-305^{\mathrm{r}}$ ), ordenadas con epígrafes con las combinaciones de las primeras letras, $A S, A S A, A S C, A S E \ldots$

El manuscrito no está fechado, pero sin duda debe datarse en los años en que Ferreras se ocupó de las combinaciones $A G$ y $A S$. En este sentido, Gili Gaya (1947: xx) rechazó la propuesta de La Viñaza, que situaba la composición del texto en 1696, ya que Ferreras «no se encontraba todavía en Madrid por aquella fecha». El estudioso reconoció que algunas de las entradas fueron redactadas con posterioridad a 1715, año en que se publicó una de las fuentes de Juan Ferreras, el «Indice de los terminos privativos del arte de la pintvra, y svs definiciones», contenido al final del primer tomo del Museo pictórico y escala óptica de Antonio Palomino de Castro y Velasco (1715). Del repertorio de Palomino, Ferreras extrajo definiciones enteras para voces de la pintura, como aguarrás y aguazo. A pesar de esta atinada observación, Gili Gaya (1947: xx) creyó que los apuntes de Ferreras contenían materiales redactados con anterioridad y decidió situar el conjunto en «el año 1700? como fecha convencional». En mi opinión, debería retrasarse la fecha de redacción de las entradas del manuscrito. Ésta debe situarse entre el 10 de agosto de 1713 (cuando, según las Actas, la Academia asigna a Ferreras la redacción de los artículos de la combinación «A ante $G \gg)$ y el 1 de agosto de 1715, día en que el académico termina su primera lectura ante la Corporación de la «explicación de voces» de la combinación $A$ ante $S$. En este lapso de tiempo Ferreras redactó y leyó ante la Academia una primera versión de las entra-

2 El f. $285^{\mathrm{v}}$ está en blanco.

3 El f. 290v está en blanco. 
das de $A$ ante $G$ (aprobadas en la junta del 13 de noviembre de 1713), trabajo que entregó en la sesión del 6 de enero de 1715. También había redactado y leído una primera redacción de las entradas de la combinación $A$ ante $S$ (labor asignada desde el 13 de noviembre de 1713).

Los apuntes que conserva el manuscrito de la Biblioteca Nacional sirvieron a Ferreras para una primera lectura de las entradas de $A$ ante $G$ y $A$ ante $S$. Son anotaciones previas a la redacción definitiva de los artículos. Un ejemplo del estado embrionario del trabajo de Ferreras se encuentra en las breves anotaciones del académico para los artículos del adverbio así, apenas cuatro líneas:

Asi mismo: tambien:

Asi que, luego que

Asi Sic adv comparatiuo: assi como el Sol

Asi Asi mediana mente. en la salud sabiduria. ${ }^{4}$

En la sesión del jueves 31 de junio de 1715 se corrige la ortografía de estas entradas que Ferreras había presentado en la Academia. En las Actas se recoge el acuerdo de enmendar la escritura de así por assí, pues

el uso de duplicar la $s$ en esta voz es tan común que se puede decir está sin controversia y que puede originarse esto de que en lo antiguo se decía ansí, convirtiéndose la $n$ en otra $s$, a que se añade que de este modo se distingue mejor del pretérito del verbo asir. ${ }^{5}$

En el $D A$ no sólo aparecen las entradas con la $s$ duplicada, sino que se amplía el espacio dedicado al adverbio assí y a las locuciones y frases hechas que lo contienen. En el repertorio se encuentra la redacción definitiva de las entradas (con una extensión de 116 líneas) ${ }^{6}$ que Ferreras no había siquiera empezado en sus primeras aproximaciones.

De hecho, el trabajo inicial de Ferreras para las combinaciones $A G$ y $A S$ fue revisado y ampliado durante un largo período de tiempo. El 14 de octubre de 1717 Vincencio Squarzafigo, Secretario de la Corporación, se ocupó de examinar y corregir los artículos redactados por Ferreras para la combinación $A G$. El resultado de

4 Ferreras (1713-i1715?: f. 301 ${ }^{\mathrm{v}}$ ).

5 Modernizo la grafía de las Actas por la dificultad de reproducir fielmente unos documentos que sólo pueden consultarse en microfilm. En las citas del manuscrito de Ferreras, del $D A$ y de su Planta he respetado las grafías originales.

6 Véase el $D A$ (I: 444-445). 
dicho trabajo se leyó en las juntas del 24 de noviembre de 1718 y del 1 de diciembre de 1718, según refieren las Actas. El propio Ferreras reescribió $A$ ante $S$ y leyó de nuevo la explicación de las voces en las sesiones de comienzos de 1720, terminando su exposición el 8 de febrero. Finalmente, Ferreras entrega, puesto en limpio, todo lo escrito hasta la fecha para las combinaciones $A G$ y $A S$ en las juntas del 25 de septiembre de 1721 y del 23 de marzo de 1724. Estas últimas versiones fueron copiadas de nuevo, bajo la supervisión de Vincencio Squarzafigo, por los escribanos encargados de preparar el manuscrito del Diccionario para la imprenta (Actas, 23-III-1724).

Así pues, de lo expuesto se deduce que los apuntes de Ferreras representan una muestra de la gestación de algunos de los artículos de las combinaciones $A G$ y $A S$. La lista de palabras que comienzan con $A S$ ejemplifica el inicio del trabajo de un académico en el proceso de selección de las voces previo a la composición de los artículos. El inventario de Ferreras es, sin duda, un punto de partida. En éste se deja constancia de un método común en la lexicografía desde sus orígenes: la consulta de diccionarios y repertorios anteriores. Tras varias de las entradas del catálogo de unidades léxicas (assemejado, assenso, assentamiento, assentar, assentido, assentir, asseverar, assiduo y assignar, en los ff. $303^{\mathrm{r}}-303^{v}$ ), Ferreras anota «Calep.», abreviatura referida al repertorio latino de Ambrosio Calepino. ${ }^{7}$

El elenco de voces escogidas para el $D A$ fue depurándose y ampliándose según avanzaba el trabajo de redacción de las entradas. La lectura de las listas de voces en las sesiones académicas suponía una primera criba: el inventario de términos de $A S$ que Ferreras leyó en la sesión académica del 31 de enero de 1714 debió de sufrir entonces sus primeras correcciones, aunque las Actas no dejan constancia de las enmiendas propuestas en dicha junta.

Posteriormente, uno de los cambios notables que sufrió la propuesta de Ferreras fue debido a la resolución por parte de los académicos de que, en los casos de $A$ ante $S$, ésta se duplicara «en todas aquellas voces que por su etimología o por el uso común y sin disputa se hallare duplicada la $s \gg$ (Actas, 20-v-1714). Si comparamos la lista manuscrita por Ferreras y el $D A$, se observan notables cambios en cuanto a la ortografía de las palabras que empiezan con as + vocal o ass + vocal. Tal como se declara en las Actas, el criterio seguido en el diccionario para determinar la grafía de dichas voces es, por un lado, etimológico, como ocurre con assamblea («de la lengua Francésa del nombre Assemblee») y con assenso (que «viene del Lat. Assensus»). Por otro lado, en algunas voces se atiende al criterio del uso, que viene determinado por la grafía que presenta el texto de las citas de las autoridades. Así ocurre en assafetida y en assaz. Finalmente, la Academia tuvo en cuenta un tercer factor, la composición morfológica de las voces, pues en el $D A$ se escriben con $s s$ todas las palabras forma- 
das mediante parasíntesis ( $a+$ tema que empieza por $s+a r)$; así ocurre, por ejemplo, con assaetear, assalarear o assalariar, ${ }^{8}$ assegundar, assegurar y assenderear .

Las correcciones en la lista inicial presentada por Ferreras no se limitaron a cuestiones ortográficas, como demuestra una comparación entre la selección de términos propuesta por el académico y el conjunto de entradas de la combinación $A S$ que contiene la impresión definitiva del $D A$. La lista de Ferreras está formada por 210 unidades léxicas, en su mayoría palabras, aunque también se encuentra alguna expresión como "Asomarse a la ventana, a la puerta». ${ }^{9}$ En el $D A$, el número de voces definidas en la combinación $A S$ aumenta considerablemente, pues asciende a 277 entradas, 66 de las cuales cuentan con segundas acepciones y unidades fraseológicas. La comparación entre la selección de palabras de Ferreras y las páginas del $D A$ también muestra la criba realizada por los académicos; éstos rehusaron definir los nombres propios propuestos por el académico (v. g. Asclepiade, Assyria y Astilejos), así como los términos asobacar, asparrago, asphodelo, asta, astilla, ${ }^{10}$ astillar, astillero y asturianos. ${ }^{11}$

Es de destacar que muchos de los nuevos lemas añadidos en el $D A$ son derivados de términos propuestos por Juan Ferreras. Por ejemplo, el académico incluye en su lista el sustantivo asco y en el repertorio se añade ascoroso, sa y ascosidad. Asimismo, junto al asear de Ferreras, el $D A$ trae el verbo y los derivados aseadamente, asearse y aseado, da; y además del asma y asmático de la lista inicial, añade asmadura, asmamiento y asmar.

El hecho de que la mayor parte de las diferencias en el elenco de voces entre el trabajo de Ferreras y el $D A$ se cifre en un aumento en el repertorio académico de voces derivadas, segundas acepciones y unidades fraseológicas denota el respeto de los académicos hacia la labor de Ferreras en cuanto a la selección de voces para la combinación $A S$. En el $D A$ incluso se introdujo un artículo redactado por Ferreras, asclepiadeo, que, en principio, había sido eliminado en la sesión académica del 4 de enero de 1720, según refieren las Actas:

8 En esta entrada, la variante léxica assalarear, no contemplada por Ferreras, se incluye en el Diccionario por encontrarse en Los problemas de Villalobos (1543).

9 Ocasionalmente, Ferreras indica que una palabra cuenta con dos o más acepciones, como ocurre con asombrar, voz que anota en dos ocasiones para señalar que equivale al latino «terrere» y que es sinónima de «Admirar» (f. 302 ), y con astrágalo, «Termino de Aquitectura» y «Yerba» (f. 304 r). En estos casos, he considerado que se trata de una sola unidad léxica para la que Ferreras propone dos significados distintos.

10 En el $D A$, hasta y hastilla aparecen con $h$ inicial, respetando la grafía del étimo. Es probable que el cambio de lugar de las voces provocara la omisión en el repertorio de las voces astillar o hastillar y astillero o hastillero.

11 En la redacción de las entradas del manuscrito de Ferreras para las voces comprendidas entre astillero y asymptotos (ff. $284^{\mathrm{r}}-285^{\mathrm{r}}$ ) ya no aparece el artículo asturianos. 
Viniendo puesta en dicha explicación la voz Asclepiadeo, nombre de una especie de versos latinos, se disputó si debía o no quedar en el Diccionario; y, habiéndose votado, quedó resuelto por mayor parte de votos que así esta voz como sus semejantes se excuse el ponerlas, respecto de no ser voces castellanas ni pertenecer a Arte Castellana, sino únicamente a la Poesía latina.

Respecto a la elaboración de las entradas, el manuscrito de Ferreras permite observar cómo se gestaban, ampliaban y corregían hasta conformar los artículos que se imprimieron en el $D A$. En el manuscrito, las entradas para las combinaciones $A G$ y $A S$ se disponen según lo acordado en la Planta definitiva del $D A$, donde se establece que

Toda la Obra del Diccionario, repartida entre los singuláres Académicos, debe traherse manuscrita à la Académia à media margen, para que se pueda añadir en su lugar lo que despues ocurriere. ${ }^{12}$

Así pues, las anotaciones de Ferreras se distribuyen en el papel en dos columnas: en una de ellas transcribe el contenido de los artículos, dejando en ocasiones espacios en blanco entre ellos (para permitir adiciones); en la otra apunta observaciones o incluye nuevas entradas.

En cuanto a los artículos de la combinación $A S$ que conservamos manuscritos por Ferreras, desde astillero a asymptotos, se observa cómo el propio académico añade y elimina algunas voces de la lista inicial. No incluye la voz asturianos y, en cambio, decide incorporar asymptotos, emmiendas que recoge el $D A$. Así pues, la omisión o la adición de voces en el repertorio académico están estrechamente ligadas al proceso de redacción del diccionario. La lista inicial de voces propuestas debía de alterarse sustancialmente incluso después de ser leída y aprobada en las juntas académicas.

En general, el trabajo de Ferreras en los artículos conservados en el manuscrito es muy incipiente. Las definiciones son muy escuetas y poco precisas y carecen de las fórmulas lexicográficas que se emplean en el diccionario. Asimismo, las autoridades son muy escasas. Un ejemplo de la imprecisión de Ferreras a la hora de redactar algunos de los artículos se encuentra en la entrada asurcar. El académico ofrece dos significados distintos para la voz:

12 «Historia de la Academia», $D A$ (I: XVIII). 
Asurcar V. A. es hacer surcos sobre los surcos de la tie/rra que esta sembrada, este verbo se formo de la voz / surco prepuesta el A. Lat. sulcum ducero mandato se/mine terra. tambien es hacer varios surcos, y no con / el orden que los hace el labrador para cultivar la tierra. ${ }^{13}$

El revisor de este artículo trató de mejorarlo, pero la redacción confusa de Ferreras provocó un error en la entrada que definitivamente se imprimió en el $D A$, pues en ella ya no aparecen dos significados distintos, uno específico ('hacer surcos en la tierra sembrada') y otro de carácter más general ('hacer surcos' sin la finalidad de cultivar la tierra). En el repertorio lexicográfico la enmienda del revisor equipara ambas acepciones presentándolas como sinónimas:

ASSURCAR. v. a. Hacer surcos sobre la tierra que está sembrada, ò hacer vários surcos con el orden que los hace el Labradór para cultivar la tierra. Es voz compuesta de la partícula A, y del nombre Surco. Lat. Humum lirare, sulcare, imporcare.

Para mostrar cómo fue avanzando el proceso de redacción y revisión de las entradas elaboradas por Juan Ferreras, es preciso detenerse en el análisis de las distintas versiones para la combinación $A G$. En el manuscrito se conservan tres redacciones de los artículos de $A G$. En la primera versión (ff. $297^{\mathrm{r}}-300^{\mathrm{v}}$ ), el número de entradas es menor. Los artículos se agrupan por familias léxicas. Las entradas relacionadas se unen mediante llaves y a cada familia corresponde un número que ordena alfabéticamente el corpus de artículos. En esta redacción faltan algunas de las informaciones que la Planta señala como imprescindibles en la microestructura de las entradas: no se indica la categoría gramatical y faltan muchas correspondencias latinas. En la segunda redacción de los artículos de $A G$ (ff. $287^{\mathrm{r}}-290^{\mathrm{r}}$ ), las entradas ya no aparecen por familias y los artículos se suceden según el orden establecido por los números marginales que aparecen en la primera versión. Apenas se observan cambios en la redacción de las definiciones: simplemente se copia el texto de los folios $297^{\mathrm{r}}-300^{\mathrm{v}}$ con alguna leve modificación, como ocurre con las entradas agarrar, donde se observa que Ferreras ha tachado una observación sobre el origen de la voz («viene de el rapere latino») y «agarrochar», donde elimina, por redundante, una alusión a «los toros». ${ }^{14}$

En esta segunda versión, Ferreras, aunque no modifica demasiado los artículos que ya tenía definidos, añade en los márgenes informaciones sobre la categoría gramatical de las palabras, así como correspondencias latinas. Incluso incorpora nuevas entradas, acompañadas de breves definiciones, como:

13 Ferreras (1713-¿1715?: f. 285 r).

14 Ferreras (1713-i1715?: f. 287r). 
Agachado. adj. el que esta escondido de el modo / dicho.

Agegado Ant agregado

Agolar V. A. voz nautica es coger la / vela y atarla ala entena en Latín/ antenis vela ligare. ${ }^{15}$

En una ocasión, anota una voz, agujeta, sin acompañarla de ningún comentario, lo que indica que los apuntes habían de ser revisados y completados. De hecho, en la tercera versión manuscrita de las entradas para $A G\left(\right.$ ff. $291^{\mathrm{r}}-296^{\mathrm{v}}$ ), agujeta aparece ya con una extensa definición.

En la última de las versiones manuscritas de la combinación $A G$ se observa cómo se perfecciona el quehacer lexicográfico de Ferreras. Este hecho se manifiesta, en primer lugar, en la distribución de las distintas acepciones, pues ahora separa, en entradas distintas, cada uno de los significados que en las versiones anteriores recogía en un mismo artículo. Para observar cómo en las sucesivas redacciones de $A G$ se va refinando la distinción de los significados de las voces, véase el ejemplo de agasajo, término al que en la primera y segunda redacciones correspondía sólo una entrada, mientras que en la tercera revisión cuenta con dos y, finalmente, tiene tres en el $D A$ :

\begin{tabular}{|c|c|c|}
\hline $\begin{array}{l}\text { Primera (f. } 297^{v} \text { ) y segunda } \\
\text { redacciones (ff. } 287^{\mathrm{r}}-287^{\mathrm{v}} \text { ) }\end{array}$ & Tercera redacción (f. 291ํㅡ) & $\begin{array}{c}\text { Diccionario de Autoridades } \\
\text { (s. v.) }\end{array}$ \\
\hline $\begin{array}{l}\text { Agassajo es el tratamiento de } \\
\text { una perssona, aquien se quiere } \\
\text { y estima, ya / con las palabras, } \\
\text { ya con las obras: con las pala- } \\
\text { bras como las de blandura, sua/ } \\
\text { vidad, y afecto; y assi la } \\
\text { perssona, que trata alos otros } \\
\text { de esta suerte, se dice, que / } \\
\text { tiene grande agassajo: en latin } \\
\text { suauiter vel blande aut dulciter } \\
\text { aloqui. Por / obra es lo que se } \\
\text { sirbe, ô se da â otra perssona, } \\
\text { monstrando en esto el afecto: } \\
\text { de don / de viene que uno que } \\
\text { regala, u hospeda a otra } \\
\text { perssona, se dice: que la rega- }\end{array}$ & $\begin{array}{l}\text { Agassajo. S. M. es la accion, } \\
\text { de agassajar de el modo pre[ce] } \\
\text { / dente. Prou. Quando una } \\
\text { perssona trata alos demas con } \\
\text { grande/suauidad blandura y ca- } \\
\text { riño se dice: que tiene grande } \\
\text { agassaj[o] / en latin magnopere } \\
\text { eloquio, aut comitate suavis / } \\
\text { Agassajo entre las mugeres } \\
\text { cortessanas se dice el refresco } \\
\text { q[ue] / dan por parte de tarde } \\
\text { alos, o las que las vissitan. En } \\
\text { latin / vrbana vespertina } \\
\text { refectiuncula. }\end{array}$ & $\begin{array}{l}\text { AGASAJO. s. m. El acto de } \\
\text { acariciar y tratar con benevo- } \\
\text { léncia y amòr à otro. Lat. Bene- } \\
\text { volentiae signa: comitas, ur- } \\
\text { banitas. Ov. Hist. Chil. fol. } \\
\text { 337. Donde fueron recibidos } \\
\text { con extraordinario agasajo y } \\
\text { alegría de todos. JAUREG. Phars. } \\
\text { lib. } 7 \text {. Oct. } 46 . \text { Partieron, pues, } \\
\text { y los contrários bandos, Que } \\
\text { al mirarse yá estrechan alian- } \\
\text { za, Alternan señas de agasá- } \\
\text { jos blandos. } \\
\text { AgASAJO. El regalo mismo, ò } \\
\text { cosa con que se re/gala. Lat. } \\
\text { Munuscula, Xenia. CorR. }\end{array}$ \\
\hline
\end{tabular}

15 Ferreras (1713-¿1715?: ff. 287 $\left.7^{\mathrm{r}}-287^{\mathrm{v}}\right)$. 


\begin{tabular}{|c|c|}
\hline $\begin{array}{l}\text { la; y agassaja / la persona que } \\
\text { recibe lo que se le da, se dice: } \\
\text { estar agassajada. La } \\
\text { etymologia / no se sabe. } \\
\text { Agassajo se dice entre las } \\
\text { mugeres en la Corte la merien- } \\
\text { da o refres/co que se da en sus } \\
\text { visitas. }^{16}\end{array}$ & $\begin{array}{l}\text { Argen. fol. 93. Rogandole } \\
\text { admitiesse aquel corto agasájo, } \\
\text { no como dón precióso, sino } \\
\text { como alhája, que havía sido } \\
\text { de su Padrre. } \\
\text { UlLoA, Rom. fol. 206. Esse, } \\
\text { con nombre de cuelga, agasájo } \\
\text { introducído. } \\
\text { AgASAJo. Se llama tambien el } \\
\text { refresco de dulces y bebídas, } \\
\text { que por las tardes se sirve en } \\
\text { las vi/sitas y otras funciónes. } \\
\text { Lat. Bellaria cum frigida, } \\
\text { aliisque reculis, quae serotinis } \\
\text { horis propinantur hospitibus. } \\
\text { BARB. Coron. fol. } 124 \text {. Un } \\
\text { agasájo abundante de tostónes } \\
\text { y de aloxa, y para la cena } \\
\text { huvo Cuajares en pepitória. }\end{array}$ \\
\hline
\end{tabular}

En cuanto a la disposición de los artículos, cabe señalar también cómo Juan Ferreras indica con un asterisco las entradas que contienen la primera acepción de una voz y que, por tanto, deben imprimirse en mayúsculas. El académico sigue así la disposición de la Planta, según la cual:

La primera vez que una Voz se pusiere en su próprio lugar de riguroso Alphabéto, se le pondrá delante un Asterisco, ò Estrellica, que al Impressór haya de significar haverla de poner toda con letras Versales, ò Mayúsculas. ${ }^{17}$

Esta precaución invita a pensar que en esta tercera redacción Ferreras preparaba ya el texto para entregarlo a la Real Academia y que ésta procediera a su revisión y su posterior preparación para la imprenta.

16 El texto está transcrito siguiendo la segunda versión del artículo. Respecto a la primera, presenta algunas pequeñas variantes: ya con las obras $2^{a}$ redac.: y ia con las obras $1^{a}$ redac.; se dice: que la regala; y agassaja la persona $2^{a}$ redac.: se dice que la regala; y la perssona $1^{a}$ redac. Además, tras el lema, Agassajo, en la $2^{a}$ redac. hay una cruz que se repite al margen y tras ésta se añade la observación «dudase si se ha de escriuir el jo con x o Jota / S. M».

17 «Historia de la Academia», DA (I: XVII). 
Ferreras no sólo dispone de forma distinta los artículos, sino que también añade muchas entradas. Entre las incorporaciones, se encuentran sustantivos que la Real Academia finalmente no incluyó en su $D A$. Se trata de las voces aga ('Cabo en la milicia'), agapetas ('hereges de el siglo Iv. llamados assi / de vna muger llamada Agage'), agareros (referido a los árabes, 'por Agar / esclaua de Abrahan, que tuuo en ella a Ismael, de quien / dicen que descienden'), agnostas ('Hereges de el IV y VI siglo') y agonicidas ('Hereges de el siglo viII'). ${ }^{18}$ Son nombres de personajes históricos que Ferreras, autor de una Historia de España en dieciséis tomos (1700-1726), consideró oportuno incluir en el diccionario. En la voz aga señala, de hecho, que es una «voz turca, pero necessaria para entender las Historias de los Turcos en lo que toca a Guerra». Recuérdese, sin embargo, que, contra el interés de Ferreras, la Real Academia, en una de sus primeras sesiones (Actas, 23-xi-1713), había acordado que del diccionario «sólo queden excluidos los nombres proprios de personas y lugares».

Además de las adiciones, Ferreras corrige de forma sustancial los artículos y añade información a las definiciones. Completa las entradas con afirmaciones sobre el origen de las voces, como ocurre en agalla, voz de la que afirma que «su etymologia se ignora, puede ser sea de la lengua de algunas delas Naciones barbaras, que entraron en España alos principios de el .v. siglo»; $;^{19}$ o en agarrar, con «etymologia dela palabra: garra: quees la mano delos animales, que tienen uñas corbas y agudas, como el Leon, Tigre, Gato y otros, antepuesta el A». ${ }^{20}$

A veces añade observaciones sobre la pronunciación y dudas sobre la grafía de las voces (que el $D A$ no recoge). En agarrochar afirma que «el cha se pronuncia con el modo usual español», ${ }^{21} \mathrm{y}$ en agassajar observa: «dudasse si sea de escribir con .J. o.X.». ${ }^{22}$

Finalmente, incluye referencias a las fuentes de los artículos. En dos ocasiones menciona a Covarrubias:

* Agegado Adj. antiquado lo mismo que Agregado. Couarr[u] / bias. Veasse: Agregado

* Agiontamiento S. M. voz antiquada. Couarrubias. es / lo mismo que aprieto. Veasse esta palabra. ${ }^{23}$

18 Véanse los ff. $291^{\mathrm{r}}, 292^{\mathrm{r}}$ y $292^{\mathrm{v}}$ de Ferreras (1713-¿1715?).

19 Ferreras (1713-¿1715?: f. 291').

20 Ibidem.

21 Ibidem.

22 Ferreras (1713-¿1715?: f. 291v). La observación sobre la grafía aparecía ya en la voz agassajo de la segunda versión de las entradas, en donde no se encuentra aún el artículo agassajar. En el f. $287^{\mathrm{r}}$ se señala en el margen de la entrada agassajo: «dúdase si se ha de escriuir el jo con x o Jota».

${ }^{23}$ Ferreras (1713-¿1715?: ff. 291 ${ }^{\mathrm{v}}$ y $\left.292^{\mathrm{r}}\right)$. 
Estas dos remisiones demuestran que Ferreras no sólo consultó el Tesoro de la lengua española o castellana (que inspira la redacción de artículos como el dedicado a ágata), sino también el Suplemento compuesto por Sebastián de Covarrubias (2001) poco antes de su muerte. Las voces agegado y agiontamiento no aparecen en el Tesoro de Covarrubias (1943), sino en las adiciones del Suplemento:

* AGIONTAMIENTOS. Vale en lengua antigua apretamientos, del nombre latino angor, oris [opresión, angustia].

* AGREGAR. Vale juntar y allegar y de allí agregado y en lengua antigua AGUEGADO. ${ }^{24}$

Los apuntes de Ferreras demuestran que el Suplemento de Covarrubias fue una de las fuentes empleadas para el $D A$. En el folio inicial del Manuscrito 6159 de la Biblioteca Nacional de España, que conserva la copia más extensa del Suplemento, unas anotaciones del siglo XVIII, de Francisco Pérez Bayer, nos informan de que la obra estuvo en manos de Vincencio Squarzafigo, Secretario de la Real Academia Española en los años de redacción y edición de su primer diccionario. ${ }^{25}$ De este manuscrito procede la copia que se conserva en la Biblioteca de la Real Academia Española (signatura Ms. O-74). ${ }^{26}$ Se trata de una versión muy reducida del texto original, pues omite las entradas dedicadas a nombres propios, prueba de que la transcripción tenía como finalidad servir de fuente a la labor lexicográfica de la Corporación.

Ferreras menciona también otra de sus obras de referencia, el Pedacio Dioscórides Anazarbeo de Andrés Laguna (1555), en los artículos agarico y aguato (ff. $291^{\mathrm{r}}$ y $292^{\mathrm{r}}$ ). A pesar de que no la cita, la tercera fuente de la que se sirvió Ferreras en sus apuntes fue, como ya señaló Gili Gaya (1947), el diccionario de términos de la pintura de Antonio Palomino de Castro y Velasco (1715). De hecho, las definiciones de los artículos de Ferreras para agicola, agrio, aguarrás y aguazo ${ }^{27}$ están copiadas del repertorio de Palomino.

24 Covarrubias (2001: s. v. ).

25 Véanse las observaciones de Francisco Pérez de Bayer: «HALLÓSE. / Entre los papeles curiosos que quedaron por fin y muerte / del Illmo. Sor. Don Gonzalo Fernández de Córdoba Comisa-/rio General Apostólico de la Santa Cruzada, de donde / le recogió Don Isidoro Vereiti Oficial mayor de la Con-/taduría del mismo Consejo, y se la dió à Don Vincencio / Squarzafigo Centurión y Arriola Académico y Secre-/tario de la Real Academia Española. / [Con otra letra:] Compréle de D. Pedro de Padilla, Mercader / de Libros de Madrid por los años 1749. / costóme seiscientos reales de vellón, y un / Alderete Antigüedades de España y África. / Franco. Pérez Bayer [rubricado]», transcrito en Sebastián de Covarrubias (2001: XXI).

26 Véase Real Academia Española (1991: 412).

27 Ferreras (1713- ¿1715?: ff. $292^{\mathrm{r}}, 294^{\mathrm{r}}$ y $\left.295^{\mathrm{v}}\right)$. 
Por lo que respecta a las autoridades, es muy reducida su presencia en los artículos. Apenas se cita el Quijote (v. g. en agareros, agazapar y agazaparsse, ageno, agible, aguachirle, aguileño, agujero), la Historia de España de Juan de Mariana (s. v. agrura) y un cantarcillo popular, «Estabase Agazapado / Pericon el de Torrijos» (s. v. agazapado).

Los apuntes para $A G$ sólo presentan algunas autoridades en la última de las redacciones de las voces de la combinación. Se demuestra que, por lo menos en el caso de Ferreras (y probablemente en el de otros académicos), el método para la elaboración de los artículos fue el siguiente: partiendo de una lista de voces, se procedió a su definición (con la ayuda de repertorios lexicográficos y fuentes de carácter enciclopédico); se ampliaron y mejoraron los artículos redactados, añadiéndose incluso nuevas entradas; y finalmente, se incorporaron las citas de autoridades que habían podido localizarse. En la fase de revisión de las entradas (de la que no tenemos testimonio manuscrito), el propio Ferreras y el encargado de revisar el material, Vincencio Squarzafigo, debieron de añadir los pasajes de las autoridades que aparecen en el diccionario. Así pues, los trabajos de redacción de las entradas del diccionario y de selección de citas de autoridades se presentan como dos ocupaciones que los académicos debían de realizar de forma paralela. Ya en la Planta acordada el 2 de diciembre de 1713, se declara cómo va a procederse a la evacuación de voces de las autoridades:

Aviéndose repartído, y de repartír, entre los Académicos, los Authóres Clásicos de la Lengua Españóla, para que cada uno desfrúte la Obra que le cupiére, apuntando las Vozes, y Phrases especiáles de nuestra Lengua; y los Textos, con que las authorizan: Debe cada uno de los Académicos observár (en las que encontrare dignas, y apuntáre) el Orden riguróso Alphabético: y al sacarlas en límpio, sea en una Cara de cada Hoja, dexando en blanco la otra; para que, sin necesitarse de hazér cópia segunda, se puédan dividir, y repartír sus apuntamientos entre los Académicos, que fuéren travajando una misma Letra: con que unos se utilizarán recíprocamente de otros. ${ }^{28}$

Así pues, en el $D A$ convivieron dos métodos lexicográficos. El primero, ejemplificado por el manuscrito de Ferreras, consistía en empezar el trabajo por la redacción de las entradas, a las que, en una revisión final, se añadían las autoridades. El segundo, que puede deducirse de la redacción de numerosos artículos del diccionario, consistía en extraer la voz y, en ocasiones, hasta la definición de las autoridades seleccionadas. Así ocurre en las voces de creación literaria que se incluyen en el

28 Real Academia Española (1713: §34). Ejemplos de este tipo de cédulas para registrar las autoridades de los textos evacuados, pueden verse en Freixas (2003: 212). 
diccionario y que proceden de las autoridades. Véanse, por ejemplo, los casos de abanicos de culpas, abernardarse, calaverar y calaverear, inventados por Quevedo, o de abemolar, término creado por Francisco López de Úbeda en su Pícara Justina.

Finalmente, el análisis de los apuntes lexicográficos de Ferreras permite constatar cómo los artículos del diccionario, desde su gestación hasta su aprobación definitiva, fueron sometidos a un arduo trabajo de revisión. En la versión impresa de los artículos de $A G$, se eliminan algunas etimologías propuestas por Ferreras con poco fundamento, como la de agachar y agacharse, para las que sugería: «su etymologia nose sabe: hase pensado viene de agatarse, que es el modo, conque se ponen los gatos para cazar los ratones».$^{29}$ Asimismo, se amplían algunos artículos, para lo cual debieron de consultarse de nuevo las fuentes que los inspiraron, como ocurre con agarico, hongo definido a partir de la información que ofrece Laguna (1555). Los académicos añaden a la entrada la cita del texto del Pedacio Dioscórides a la que remitía (sin transcribirla) el artículo de Ferreras.

También se suprimen informaciones poco relevantes, como el hecho de que la agalla o agallas del pescado «son las mismas partes immediatas ala cabeza: que el Italiano y Frances llaman la Oreja de el pescado». ${ }^{30} \mathrm{Y}$, sin duda, los cambios más interesantes que sufren las entradas son las modificaciones debidas a la inclusión de las autoridades en las últimas fases de revisión del texto. Sirvan de muestra los casos de agarrochado y agazapado, en los que la cita en el diccionario de autoridades de reconocido prestigio, como La Celestina, y las obras de José de Pellicer y Miguel de Cervantes, provoca que se eliminen las observaciones de Ferreras acerca de que se trata de voces propias de un estilo bajo y vulgar:

\begin{tabular}{|c|c|}
\hline $\begin{array}{l}\text { Tercera redacción de Ferreras de los } \\
\text { artículos de AG (ff. 291 } 291^{r} \text { ) }\end{array}$ & $D A$ \\
\hline $\begin{array}{l}\text { Agarrochado. Adj. passiuo de Agarrochar / } \\
\text { Prov. por esta anologia [sic] se suele decir, de } \\
\text { el que esta muy / lastimado y sentido de inju- } \\
\text { rias o valdones, que esta agarro/chado. En } \\
\text { Latin: Injuriis laussitus; pero esta phrase es } \\
\text { muy / baja, y poco ussada de los Autores de } \\
\text { buen estilo. }\end{array}$ & $\begin{array}{l}\text { AGARROCHADO, DA. part. pas. Lastimádo } \\
\text { ò / herído con garróchas. Lat. Missilibus, } \\
\text { jaculis / exagitatus. CALIXT. Y MELIB. fol. } 5 \text {. } \\
\text { Todos rom/pen pungídos, y agarrochádos } \\
\text { como ligéros to/ros. Pellic. Argen. part. 2. fol. } \\
\text { 103. Com impie/dád inhumana morían à sus } \\
\text { manos agorrochádos [sic]/ como fieras. }\end{array}$ \\
\hline $\begin{array}{l}\text { Agazapado Adj. es estar escondido esperando } \\
\text { lo que resulta. / En latin occultum spectare rei } \\
\text { euentum. Es voz vaja y burl[es] / ca. Estabasse } \\
\text { Agazapado Pericon el de Torrijos }\end{array}$ & $\begin{array}{l}\text { AGAZAPADO, DA. part. pas. Escondido, } \\
\text { ocultá/do, como acechando. Lat. Humi dejectus. } \\
\text { Hu/mi strato córpore occultus. CERV. Persil. lib. } \\
\text { I. / cap. 4. Yá agazapádos, yá inclinádos, yá } \\
\text { agobiádos à el suelo, yá en pie, y derechos. }\end{array}$ \\
\hline
\end{tabular}

29 Ferreras (1713-¿1715?: f. 291 $\left.{ }^{\mathrm{r}}\right)$.

30 Ibidem. Cf. DA, s. v. 
Se demuestra, pues, cómo en un diccionario basado en las citas de un extenso corpus de autoridades ${ }^{31}$ la labor lexicográfica resultó muy compleja y en ella se interfirieron y complementaron las labores de definición y las de ilustración del uso de las voces mediante ejemplos representativos.

\section{REFERENCIAS BIBLIOGRÁFICAS}

Actas. Real Academia Española, Actas, manuscrito de los resúmenes de las actas de las sesiones de la Corporación en los años 1713-1739, Archivo de la Real Academia Española [sin topográfico].

Covarrubias y Horozco, Sebastián de (1943 [1611]): Tesoro de la lengua castellana o española, ed. según la impresión de 1611, con las adiciones de Benito Remigio Noydens publicadas en la de 1674 [Madrid, Melchor Sánchez], ed. Martín de Riquer, Barcelona, Horta [reimpr. Barcelona, Altafulla, 1987].

— (2001 [1611]): Suplemento al «Tesoro de la lengua española castellana», ed. Georgina Dopico y Jacques Lezra, Madrid, Polifemo.

DA. Real Academia Española (1726-1739): Diccionario de la lengua castellana, Madrid, Imprenta de Francisco del Hierro-Herederos de Francisco del Hierro [reimpr. facsímil, Diccionario de Autoridades, Madrid, Gredos, 1990].

FERRERAs, Juan de (1713-¿1715?): «Artículos para el Diccionario de la lengua castellana», Biblioteca Nacional de España, Ms. 9.232, ff. 284 $4^{\mathrm{r}}-305^{\mathrm{r}}$.

Ferreras, Juan (1700-1726): Historia de España, Madrid, Francisco de Villa-Diego, 16 vols.

FreIXAS, Margarita (2003): Las autoridades en el primer Diccionario de la Real Academia Española, tesis dirigida por José Manuel Blecua, Bellaterra, Universitat Autònoma de Barcelona.

Gallina, Annamaria (1959): Contributi alla storia della lessicografia italo-spagnola dei secoli XVI e XVII, Florencia, Olschki.

Gili Gaya, Samuel (1947): Tesoro lexicográfico (1492-1726), I (A-G), Madrid, Suministros Escolares y Científicos.

Laguna, Andrés (1555): Pedacio Dioscórides Anazarbeo, acerca de la materia medicinal y de los venenos mortíferos, Amberes, Iuan Latio.

31 En Freixas (2003) catalogué todos los textos recogidos en las listas de autoridades y de abreviaturas que contienen los Preliminares de los tomos del $D A$. La suma de obras citadas asciende a 755. 
Lázaro Carreter, Fernando (1972): Crónica del «Diccionario de Autoridades» (1713-1740), Madrid, Real Academia Española.

Palomino de Castro y Velasco, Antonio (1715): «Indice de los terminos privativos del arte de la pintvra, y svs definiciones», Museo pictórico y escala óptica, I, Theorica de la pintvra, Madrid, Lucas Antonio de Bedmar, ff. Hhhh2r $-\mathrm{Mmmm}^{\mathrm{v}}$.

Real Academia Española (1713): Planta y methodo que, por determinacion de la Academia Española, deben observar los academicos en la composicion del nuevo Diccionario de la Lengua Castellana; a fin de consegvir su mayor uniformidad, Madrid, Imprenta Real, por José Rodríguez y Escobar.

- (1991): Catálogo de manuscritos de la Real Academia Española, en Anejos del BRAE, L.

VIÑAZA, Conde de la (1893): Biblioteca histórica de la filología castellana, Madrid, Real Academia Española-Imprenta y Fundición de Manuel Tello. 